\title{
Factors Affecting the Performance of Micro and Small Scale Enterprises: Experience from North Shewa Zone, Ethiopia
}

\author{
Woldetsadik Kagnew Abebaw ${ }^{1}$, Sisay Mulate, , Lemma Nigussie $^{1, \text { * }}$ \\ ${ }^{1}$ Department of Management, DebreBerhan University, DebreBerhan, Ethiopia \\ ${ }^{2}$ Department of Accounting and Finance, DebreBerhan University, DebreBerhan, Ethiopia \\ Email address: \\ woldkagn@gmail.com (W. K. Abebaw), sisaym66@gmail.com (S. Mulate), noh2001@gmail.com (L. Nigussie) \\ ${ }^{*}$ Corresponding author
}

\section{To cite this article:}

Woldetsadik Kagnew Abebaw, Sisay Mulate, Lemma Nigussie. Factors Affecting the Performance of Micro and Small Scale Enterprises: Experience from North Shewa Zone, Ethiopia. Journal of Investment and Management. Vol. 7, No. 2, 2018, pp. 70-76. doi: $10.11648 /$ j.jim.20180702.14

Received: May 6, 2018; Accepted: May 25, 2018; Published: June 18, 2018

\begin{abstract}
Research has shown that there are factors that contribute to success or failure in small enterprises in the government departments in the world. An environment conducive for the growth of MSEs is required, and this has necessitated an investigation into the factors affecting the performance of SMEs in North Shewa Zone, Ethiopia. The general objective of the study is to investigate factors that influencing the performance of micro and small enterprises in North Shewa Zone town, Ethiopia. The research used probability; strata sampling techniques. The researcher selected 386 respondents out of 11,244 populations. For data analysis, we have used OLS regression analysis Pearson correlation Coefficient. Based on the data collected from 386 MSEs in North Shewa Zone, Ethiopia, the results showed that there is a significant positive relationship between entrepreneurship, labour skill, infrastructure, finance, leadership skill and the performance of SMEs. This study recommends that the MSE businesses and government should effectively address the infrastructure especially in terms of electricity, work place, market place and roads in order to increase their performance.
\end{abstract}

Keywords: MSEs, Performance, Finance, Leadership, Labor Skill, Ethiopia

\section{Introduction}

\subsection{Background of the Study}

Small businesses are the back bone of many economies across the globe. It is one of the important segments of the economic growth. It initiates change and works for the goods of people. Micro and small enterprises (MSEs) make important contributions to the development of many countries economy. The growth of a healthy, competitive MSEs sector will be maximized when there is a strong enterprise culture in the society at all levels; a continuous growth in the quality stock of independent business; maximum potential for growth of existing small businesses: and a highly supportive economic, social and stakeholder environment [1]. In developing countries they are seen as a major 'self-help' instrument for poverty eradication. Today in
Ethiopia the importance of small business enterprises though job creation, source of wealth for owners, source of income for government GDP etc.., becomes increasing and the government also gives attention to them. However those small business enterprises have not been able to contribute substantially as needed to the economic development of the country which is particularly because of financial, production, marketing and other problems. These problems are still major bottlenecks to their development. Lack of adequate finance and credit has always been a major problem of Ethiopian small business [9].

Small and Medium Enterprises are of great importance to the Ethiopian economy since it can be a mechanism to stimulate economic growth, thereby employment creation, in the country. This study attempted to establish whether a lack of skilled human resources, poor financial management, a lack of management skills and economic variables are factors 
which impact on the performance of Small and Medium Enterprises in Ethiopia. It furthermore also attempted to establish whether there are other internal factors over and above those identified, which exert an influence on the performance of MSEs in the North Shewa Zone, Ethiopia.

It can be stipulated that performance may be measured from different perspectives. Some of the core measures of performance are Profitability, turnover, growth in the labor force and market share [10, 16, 18, 4]

\subsection{Statement of the Problem}

As the world economy continues to move towards increased integration, some of the greatest opportunities for Microand Small Sized Enterprise (MSEs) will derive from their ability to participate in the global marketplace. It is generally accepted that SMEs are becoming increasingly important in terms of employment, wealth creation, and the development of innovation. However, there are considerable doubts about the quality of management in this sector with policy-makers suggesting that there are particular weaknesses in innovation, a lack of financial acumen, marketing, entrepreneurial flair, practical knowledge, and human resource management. As a result, many firms do not reach their full potential and fail to grow.

Research indicates that small businesses tend to have a higher failure rate as compared to large organisations, although they are commonly perceived as an engine of a country's economy [2, 13]. Starting and operating a small business includes a possibility of success as well as failure. Because of their small size, a simple management mistake is likely to lead to sure death of a small enterprise hence no opportunity to learn from its past mistakes. Lack of planning, improper financing and poor management have been posited as the main causes of failure of small enterprises [14]. Lack of credit has also been identified as one of the most serious constraints facing MSEs and hindering their development [19].

Business success is about the achievement of goals and objectives of a company, which is not explicitly defined [17, 16] There are various ways to measure business success that includes survival, profits, return on investment, sales growth, number of personnel employed, happiness, corporate reputation, and others [24]. Education is one of the factors that impact positively on growth of firms. Those entrepreneurs with larger stocks of human capital, in terms of education and (or) vocational training, are better placed to adapt their enterprises to constantly changing business environments. Infrastructure as it relates to provision of access roads, adequate power, water, sewerage and telecommunication has been a major constraint in the development of MSEs. Research has shown that there are factors that contribute to success or failure in small enterprises in the government departments in the world. Unemployment is somewhat high, partly due to a lack of the much-needed efforts to create jobs and also the current state of the economy. Job creation and poverty alleviation are two pressing challenges facing Ethiopia today. Ethiopia's capacity to address the high unemployment and poverty levels is partly hampered by the nose diving economic conditions due to sanctions and somewhat a high rate of inflation. The encouragement and support of MSEs in Ethiopia is therefore important in the light of the many economic challenges which the country is currently experiencing. It becomes important to promote MSEs as they are a vehicle for employment creation and economic growth. An environment conducive for the growth of MSEs is required, and this has necessitated an investigation into the factors affecting the performance of MSEs in North Shewa Zone, Ethiopia.

Moreover, over the last six years (2004-2009), the Ethiopian economy has markedly grown. This promising stride has provided Ethiopia with ample opportunity to be categorized under the top performing economies in SubSaharan Africa. Overall economic performance measured by growth in real Gross Domestic Product (GDP) has registered 11.5 percent on average. During the same period, the average growths attained in agriculture, industry and service sectors were $10.8 \%, 10.1 \%$ and $13.0 \%$, respectively. The country's real GDP has grown tremendously from Birr 66 billion in the year 2000 to Birr 135 billion in the year 2009 not only at aggregate level but also at all levels of economic sectors (Agriculture, industry, construction, services, and the public. As part of the industrial sector, MSEs are increasingly becoming popular and important in the Ethiopian economy as they would play a decisive role in contributing to employment generation, poverty reduction and the opening of wider distribution of wealth and opportunities. However, MSEs have faced a number of constraints, like lack of access to markets, finance, business information; lack of business premises; low ability to acquire skills and managerial expertise; low access to appropriate technology and poor access to quality business infrastructure [27, 9].

\subsection{Objectives of the Research}

\subsubsection{General Objective}

Thegeneral objective of the study is to assess factors affecting the performance of MSEs in North Showa zone.

\subsubsection{Specific Objectives}

The objectives of the paper are:

a) To examine the sources of finance or funds available for the start-up and the expansion of MSEs.

b) To Identify the contextual factors that affect the performance of MSEs.

c) ToIdentify the internal factors that affect the performance of MSEs.

d) ToRecommend possible solution to alleviate the problem of MSEs.

e) To establish whether a lack of skilled human resources contributes to the poor performance of SMEs in North Showa zone, Ethiopia;

\subsection{Research Hypothesis}

$\mathrm{H}_{1}$ : technology related problems does significantly affect the performance of MSEs in North Showa Zone. 
$\mathrm{H}_{2}$ : market linkage does significantly affect the performance of MSEs in North Showa Zone.

$\mathrm{H}_{3}$ : financial issue does significantly affect the performance of MSEs in North Showa Zone
$\mathrm{H}_{4}$ : legal issues doessignificantly affect the performance of MSEs in North Showa Zone

$\mathrm{H}_{5}$ : leadership does significantly affect the performance of MSEs in North Showa Zone

Table 1. Definitions of Micro and small enterprises in Ethiopian context.

\begin{tabular}{llll}
\hline Type of Enterprises & Kind of enterprise & Working capital in birr & Number of employees \\
\hline \multirow{2}{*}{ Micro enterprises } & Industry & less or equal to 100,000 & $<=5$ \\
& Service & less or equal to 50,000 & $<=5$ \\
\multirow{2}{*}{ Small enterprises } & Industry & $100,001-1.5$ million & $6-30$ \\
& Service & $50,001-500,000$ & $6-31$ \\
\hline
\end{tabular}

Source: under NSZ TEVT leading Enterprise capacity building.

Characteristics of small and medium sized industries:

Characteristics of SMI by their Nature, Definition and Classification

The level of economic development of a country generally, determines the shape, pattern and growth of the industrial sector. In addition to the economic climate, the environment under which the manufacturing sector operates, determines the composition, shape, structure and operation of the industry.

The general characteristics of the small and medium sized industries includes:

(i) The Manager handles all aspects of Management.

(ii) Suffers from difficulty in obtaining finance,

(iii) Limited market - products intended to serve local markets.

(iv) Maintains no proper accounts of costs and revenues.

(v) Lack of competent personnel with sufficient educational background.

\section{Method}

\subsection{Research Design}

The study is mainly descriptive, both quantitative and qualitative in nature. This method was used to gain an insight in to the research problem and to identify factors that lead to failure of small businesses in DebreBirhan, Baso and Worana, Ankober, Showa Robit, Debresina, and Deneba.

\subsection{The Conceptual Framework}

Conceptual framework means that concepts that relate to one another were used to explain the research problem. Since business performance is influenced by both internal and contextual factors, operators need to understand what influences businesses to reach peak performance. The contextual factors include politico-legal, working premises, technological, infrastructural, marketing and financial factors. (Wanjiku, 2009:81-82). Nevertheless, the factors must be closely monitored to ensure that stringent measures are taken within the best time to either take advantage of the opportunities or combat the threats found in the external environment. The internal factors that influence the firm's performance can be classified as management and entrepreneurial factors. To align the conceptual framework with the research objectives, business performance is the dependent variable whereas politico-legal, working premises, technological, infrastructural, marketing, financial, management and entrepreneurial factors are all independent variables. The relationship can be expressed and shown in figure 1 .

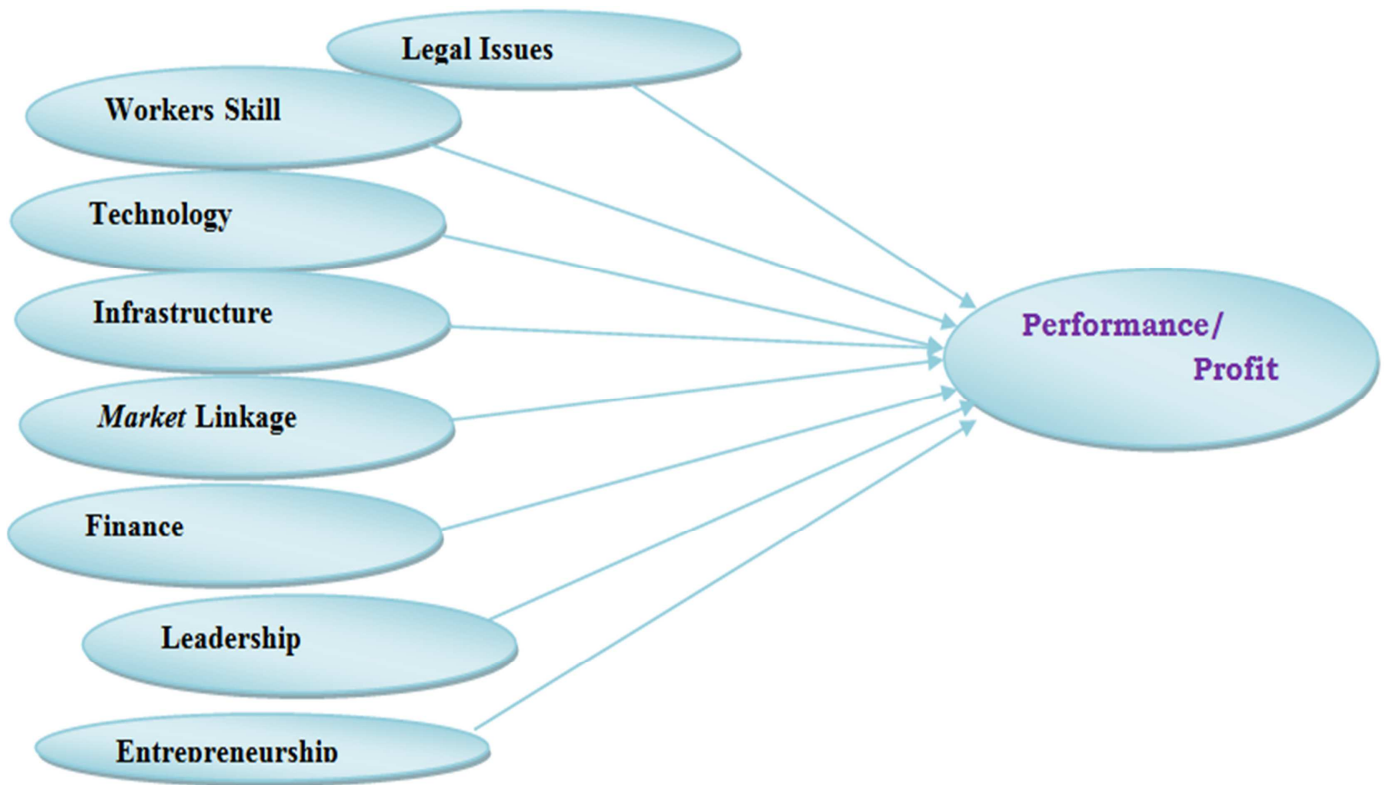

Figure 1. Frame work of the research that shows the relation between the independent variables with dependent variable. 


$$
\text { Profit }=\beta_{0}+\beta_{1} \text { LEGAL }+\beta_{2} \text { SKILL }+\beta_{3} \text { TECH }+\beta_{4} \text { INFR }+\beta_{5} \text { MARK }+\beta_{6} \text { FINA }+\beta_{7} \text { LEAD }+ \text { ENT }+ \text { e. }
$$

Profit $=$ total profit; LEGAL $=$ legal issues; SKILL $=$ workers skill; TECH $=$ technology related problems; INFR = infrastructure related problems; MARK = market linkage problems; $\mathrm{FINA}=$ financial related variables; $\mathrm{LEAD}=$ leadership related problem.

In this study profitability was opted to measure performance of these MSEs. This is mainly because of the following three reasons. First, as the pilot study clearly indicates these MSEs are more focusing on profitability than other modes of performance measures. Second, the MSEs were not applying balanced score card to measure their overall performance. Third, as recommended by Rami and Ahmed [23] a profit has been widely adopted by most researchers and practitioners in business performance models.

\subsection{Sampling Technique}

The study used the probability sampling method. The population is 11,244 enterprises in the North Shewa zone. Which are large and the researcher wants to make sure that the sample that comes out of it is representative. The probability sampling type ensures that every SME firm has an equal chance of being selected for the purposes of the survey. In random sampling, the respondents from various business types will select randomly $60 \%$ from the small business managers, $80 \%$ from the medium level enterprises.

The following formula was used for the calculation of the sample size since it was relevant to studies where a probability sampling method was used [29].

$$
\mathrm{n}=\left[\frac{\left.\frac{P(1-P)}{A^{2}+\frac{P(1-P)}{N}}\right]}{R}\right.
$$

Where, $\mathrm{n}=$ sample size required $=$

$\mathrm{N}=$ number of population $=11244$

$\mathrm{P}=$ estimated variance in the population $=50 \%$

$$
\begin{aligned}
& A=\text { margin of error }=5 \% \\
& Z=\text { confidence level }=1.96 \text { for } 95 \% \text { confidence }^{5} \\
& R=\text { estimated response rate }=96 \%
\end{aligned}
$$$$
\mathrm{n}=\left[\frac{\left.\frac{.5(1-0.5)}{0.95^{2}}+\frac{.5(1-.5)}{11244}\right]}{.96}\right] 386[8]
$$

Since respondents are selected from the sample unit within the total population in North showa zone. Most of the enterprises have faced with certain similar problems.

Random sampling method (which is simple random sampling method) is used to select enterprises for the whole population just to undertake and gather information with regards to their feeling to the delivery of products by the company. 386 enterprises figured out.

The study employed stratified random simple sampling. The population was segregated into several mutually exclusive subpopulations or strata herein referred to as business categories as shown in appendixes. There were 5628 SMEs in the selected woreda Towns.

The research applied proportionate stratification that is based on the stratu's share of the total population to come up with the sample in each stratum. The actual businesses interviewed were arrived at by using simple random procedures to draw the sample from each stratum. The sample size was determined by the following formula [30].

$$
\mathrm{n}=\frac{N}{1+N(e)^{2}} \frac{11244}{1+11244(0.05)^{2}}=386.25 \approx 386
$$

Where:

$\mathrm{n}$ - is the sample size,

$\mathrm{N}$ - is the population size $=11244$

$\mathrm{e}$ - is the level of precision $=5 \%$

In this case $\mathrm{N}$ is $11244, \pm 5 \%$ Precision Levels where Confidence Level was $95 \%$ and $\mathrm{P}=.5$

Hence, the sample size of the study 386 .

Sample size determination for each stratus (woredas) $=$ single woredapopu. $/$ Sampling frame * sample size

Table 2. Sample Size PerWeredas.

\begin{tabular}{llllll}
\hline No. & Sample woredas & Total MSE & Total sample $=\mathbf{n}$ & Proportion & Sample selected \\
\hline 1 & Debrebirhan & 1,544 & 386 & 0.274343 & 106 \\
2 & DebrSina & 929 & 386 & 0.165068 & 64 \\
3 & Shewarobit & 1716 & 386 & 0.304904 & 118 \\
4 & Deneba, & 418 & 386 & 0.074271 & 29 \\
5 & Ankober & 430 & 386 & 0.076404 & 29 \\
6 & Basso and worena & 591 & 386 & 0.105011 & 40 \\
& Total & 5,628 & & 1 & 386 \\
\hline
\end{tabular}

\subsection{Model Specification}

The basic research approach which playing in this study relies on the regression model of MSEs performances is similar to the previous studies. The dependent variable will be taken as turnover, which has to be explained by various characteristics of the MSEs Interpersonal skills, The human resources skills, Strategic management factors, Marketing management factors, Entrepreneurial management factors, Macroeconomic Environment Factors, External Environmental Factors, Globalization Factors, The management directing function, Incentive policies, Finances/Capitalization Factors and Technological factors. Therefore, the basic regression model that applied in this 
study is as follows:

profit $=\beta_{0}+\beta_{1}$ LEGAL $+\beta_{2}$ SKILL $+\beta_{3}$ TECH $+\beta_{4}$ INFR

$+\beta_{5}$ MARK $+\beta_{6}$ FINA $+\beta_{7}$ LEAD + ENT + e.

$\mathrm{Y}=$ profit

$\mathrm{X}_{1}=$ Regulation and Policy

$\mathrm{X}_{2}=$ The human resources skills
$\mathrm{X}_{3}=$ technology related problems

$\mathrm{X}_{4}=$ infrastructure related problems;

$\mathrm{X}_{5}=$ market linkage problems

$\mathrm{X}_{6}=$ financial related variables;

$\mathrm{X}_{7}=$ entrepreneurship,

$\mathrm{X}_{8}=$ Leadership

\section{Results and Discussions}

\subsection{Descriptive Statistics}

Table 3. Descriptive statistics for final sample of 386 enterprises.

\begin{tabular}{|c|c|c|c|c|c|}
\hline \multicolumn{6}{|c|}{ Descriptive Statistics } \\
\hline Variables & $\mathbf{N}$ & Minimum & Maximum & Mean & Std. Deviation \\
\hline Lprofit & 386 & 3.48 & 4.85 & 4.2090 & .20243 \\
\hline LEGAL. & 386 & 12.00 & 30.00 & 24.0738 & 5.36601 \\
\hline SKILL. & 386 & 6.00 & 28.00 & 18.0492 & 6.60497 \\
\hline TECH. & 386 & 6.00 & 20.00 & 14.4909 & 4.38388 \\
\hline INFR. & 386 & 6.00 & 25.00 & 16.8951 & 6.68170 \\
\hline MARK. & 386 & 5.00 & 35.00 & 24.6227 & 9.54703 \\
\hline LEAD. & 386 & 6.00 & 30.00 & 17.7640 & 6.60581 \\
\hline ENT. & 386 & 5.00 & 30.00 & 18.0130 & 6.65178 \\
\hline
\end{tabular}

Source: researchers' survey finding 2015

Notes: variable definition: lprofit $=$ total profit; $\mathrm{LEGAL}=$ legal issues; SKILL = workers skill; TECH = technology related problems; INFR = infrastructure related problems; MARK $=$ market linkage problems; FINA $=$ financial related variables; $\mathrm{LEAD}=$ leadership related problem, ENT=Entrepreneurship.

Descriptive statistics can be obtained in a number of different ways, using frequencies and descriptive. For continuous variables it is easier to use descriptive, which provides summary statistics such as mean, maximum, minimum, standard deviation. Table 2 shows the descriptive statistics for the variables employed in the model.

\subsection{Correlation Analysis}

The result shows that the legal related issue variable as measured by legal issue (LEGAL) is positively correlated to the performance, with a coefficient of $r=0.099$, which is also significance at $\mathrm{p}<0.01$. Secondly, the labor skill related variable by labor skill is found to be positive and significantly correlated with performance, $r=0.61, p<0.01$. This implies that an increase in labor skills results in an increase in profits and production output of MSEs. Thirdly, the leadership (management) skill is found to be significantly correlated with performance, $\mathrm{r}=0.608, \mathrm{p}<0.05$. This finding is consistent with previous studies conducted by Kinyua
(2014). This implies that an increase in management skills results in an increase in profits and production output of MSEs. Findings also indicate that infrastructure is found to be positive and significantly associated with profits ( $\mathrm{r}$ $=0.710, \mathrm{P}>0.01)$. Findings also indicates that access to finance was significantly associated with profits $(\mathrm{r}=0.634$, $\mathrm{P}<0.01)$. This implies that an increase in access to finance results in an increase in profits of MSEs. Finally, correlation results indicate that technology and market access were not found to be significantly associated with profits. This implies that an increase in technology and market access did not result in an increase in profit MSEs in the study area.

Dimensions relationship with Performance:

1) Legal Issues $\rightarrow$ Performance of MSMEs $=0.099^{* *}$, $\mathrm{P}<0.01$ );

2) Skills $\rightarrow$ Performance of MSMEs $=610 * *, P<0.01$ );

3) Infrastructure $\rightarrow$ Performance of MSMEs $=0.704 * *$, $\mathrm{P}<0.01$;

4) Market Linkage $\rightarrow$ Performance of MSMEs $=0.355^{* *}$, $\mathrm{P}<0.01)$

5) Financial Issue $\rightarrow$ Performance of MSMEs $=0.4858 * *$, $\mathrm{P}<0.01$ ) and;

6) Leadership $\rightarrow$ Performance of MSMEs $=0.6086^{* *}$ $\mathrm{P}<0.01)$

Table 4. Correlation Matrix.

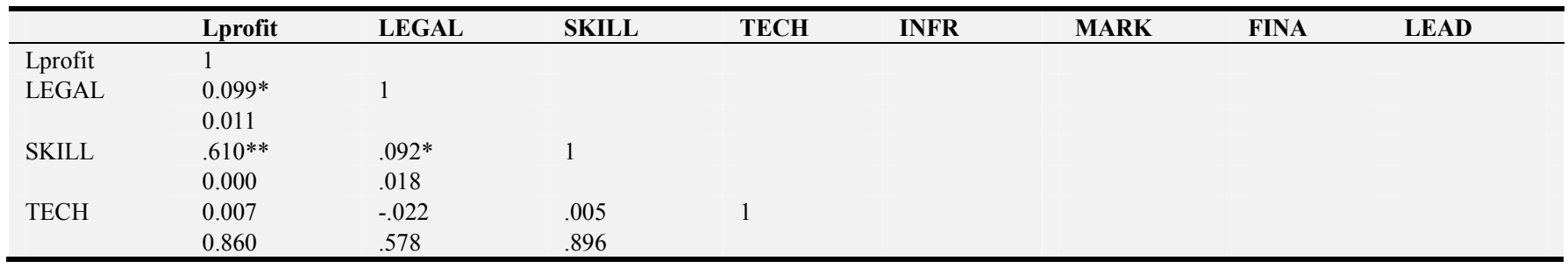




\begin{tabular}{|c|c|c|c|c|c|c|c|c|}
\hline & Lprofit & LEGAL & SKILL & ТЕСН & INFR & MARK & FINA & LEAD \\
\hline \multirow[t]{2}{*}{ INFR } & $0.704 * *$ & $.132 * *$ & $.580 * *$ & .057 & 1 & & & \\
\hline & 0.000 & .001 & .000 & .141 & & & & \\
\hline \multirow[t]{2}{*}{ MARK } & 0.026 & .026 & .016 & .011 & .008 & 1 & & \\
\hline & 0.505 & .503 & .687 & .779 & .840 & & & \\
\hline \multirow[t]{2}{*}{ FINA } & $0.634 * *$ & $.107 * *$ & $.540 * *$ & .036 & $.579 * *$ & -.009 & 1 & \\
\hline & 0.000 & .006 & .000 & .358 & .000 & .816 & & \\
\hline LEAD & $0.596 * *$ & $.101 * *$ & $.498 * *$ & -.043 & $.611 * *$ & -.046 & $.501 * *$ & 1 \\
\hline \multirow[t]{2}{*}{ ENT } & $0.630 * *$ & $0.148 * *$ & $0.670 * *$ & 0.022 & $0.600 * *$ & 0.020 & $.599 * *$ & $0.532 * *$ \\
\hline & 0.000 & 0.000 & 0.000 & 0.581 & 0.000 & 0.604 & 0.000 & 0.000 \\
\hline
\end{tabular}

Source survey finding 2015

**. Correlation is significant at the 0.01 level (2-tailed).

*. Correlation is significant at the 0.05 level (2-tailed).

\subsection{Regression Analysis}

In order to determine the effect of factors on performance of MSEs and test the study hypotheses, the combined independent variables (access to finance, leadership skills, labor skill, legal and policy issues, technology, market access, entrepreneurship and infrastructure) were regressed on the dependent variable (performance of MSEs).

The overall model is significant $(\mathrm{F}-$ statistic $=152.45$, $\mathrm{P}<0.01$ ), and consistent with prior studies, the model's explanatory power is high (adjusted $\mathrm{R}^{2}=0.610$ ). The study F- test value shows statistical significance at level better than 0.01 , indicating that the relationship between the dependent and independent variables are meaningful.

Table 5. Result of ordinary least square regression.

\begin{tabular}{lllll}
\hline Variable & B & Std. error & t & P-value \\
\hline Constant & 3.699 & 3.159 & 108.99 & 0.000 \\
LEGAL & 0.001 & 10.48 & .364 & 0.716 \\
SKILL & 0.452 & 0.324 & 6.19 & 0.000 \\
TECH & 0.001 & 0.486 & 0.704 & 0.482 \\
INFR & 0.728 & 1.349 & 10.048 & 0.000 \\
MARK & 0.093 & 0.054 & 1.700 & 0.090 \\
FINA & 0.265 & 5.158 & 7.701 & 0.000 \\
LEAD & 0.190 & 0.129 & 5.088 & 0.000 \\
ENT & .082 & .041 & 2.556 & .001 \\
F & 151.45 & & & \\
Significance & 0.000 & & & \\
R & 0.62 & & & \\
Adj. R ${ }^{2}$ & 0.61 & & & \\
$\mathrm{~N}$ & 386 & & & \\
\hline
\end{tabular}

Source: researchers' survey finding 2015

Results of regression analysis (Table 5) reveal that access to finances was found to significantly affect performance of MSEs $(\mathrm{P}=0.000, \mathrm{P}<0.05)$. This implies that an increase in access to finance results in an increase in profits of MSEs. Hence the null hypothesis that Accesses to finance does not significantly affect performance of MSEs in North Shewa was rejected.

\section{Conclusions}

lprofit $=\beta_{0}+\beta_{1}$ LEGAL $+\beta_{2}$ SKILL $+\beta_{3}$ TECH $+\beta_{4}$

INFR $+\beta_{5}$ MARK $+\beta_{6}$ FINA $+\beta_{7}$ LEAD + e.

lprofit $=$ total profit; LEGAL $=$ legal issues; SKILL $=$ workers skill; TECH = technology related problems; INFR = infrastructure related problems; MARK = market linkage problems; $\mathrm{FINA}=$ financial related variables; $\mathrm{LEAD}=$ leadership related problem

Findings also indicate that management (leadership) skills) and entrepreneurship were found to significantly affect performance of SMEs $(\mathrm{P}=0.000, \mathrm{P}<0.01)$. Finally, findings indicate that legal and policy issues, technology and market access were not found to significantly affect performance of MSEs.

\section{References}

[1] Sharmilee Sitharam and Muhammad Hoque (2016). Factors affecting the performance of small and medium enterprises in KwaZulu-Natal, South Africa. Problems and Perspectives in Management, 14 (2-2).

[2] Bloch, H., \& Bhattacharya, M. (2016). Promotion of innovation and job growth in small and medium-sized enterprises in Australia: Evidence and policy issues. Australian Economic Review, 49 (2), 192-199. https://doi.org/10.1111/1467-8462.12164.

[3] Bokea, C., A. Dondo and J. Mutiso (2000). "Physical infrastructure". In Andrew Mullei and A. Bokea (eds). Micro and small enterprises in Kenya: Agenda for Improving the Policy Environment. Nairobi: ICEG.

[4] Du plessis, P. J., Jooste, C. J \& Strydom, J. W. 2005. "Applied strategic marketing. Sandton": Heinemann Publishers (Pty) Ltd.

[5] Eshetu Bekele \& Zeleke Worku. (2008). "Factors that Affect the Long-term Survival of Micro, Small, and Medium Enterprises in Ethiopia." South African Journal of Economics, 10 (2):76-81.

[6] Farmers' Organizations in Kedah, World Review of Business Research, 3 (1), pp. 80-102.

[7] Franz, L. 2000. "Making Small Business"- Engineering News. South Africa: 11-17 August.

[8] Geoffrey Marozyk, David Dematto, David Festinger (2005), "Essential of research design and methodology", John whiley and sons, inc, Canada.

[9] Hailay Gebretinsae PhD (2007). "Entrepreneurship and Small Business Management", $2^{\text {nd }}$ ed. Mekeleuniversity, Addis Ababa Ethiopia. 
[10] Harif, M. M., Hoe, C. H. \& Ahmad, M. I. (2013). The Financial and Non-Financial Performance Indicators of Paddy.

[11] John Adams and Robert Reasid (2010), "Research Methods for Graduate Business and Social Science Studies", Asian pacific pie ltd.

[12] Kothari, C. R. (2004). "Research Methodology: Methods and Techniques." University of Rajasthan.

[13] Lo, M. C., Wang, Y. C., Wah, C. R. J., \& Ramayah, T. (2016). The critical success factors for organizational performance of SMEs in Malaysia: A partial least squares approach. Revista Brasileira de Gestão de Negócios / Review of Business Management, $\quad 18 \quad 370$. https://doi.org/10.7819/rbgn.v18i61.3058.

[14] Longenecker, J. G., Petty, C. W., Moore, J. W. and Palich, L. E. (2006). "Small Business Management, An entrepreneurial emphasis". London: Thomson South Western.

[15] Marom, S., \& Lussier, R. N. (2014). A business success versus failure prediction model for small businesses in Israel. Business and Economic Research, 4 (2), 63-81. https://doi.org/10.5296/ber.v4i2.5997.

[16] Matsotso, M. L. \& Benedict, H. O. (2014). Non-Financial Performance Measures in Small Medium Enterprises.

[17] Ngwangwama, M. M., Ungerer, M., \& Morrison, J. (2013). An exploratory study of key success factors for business success of companies in the Namibian tertiary industry. International Journal of Innovations in Business, 2 (6), 604629.

[18] Nieman, G \& Pretorius, M. 2004. "Managing Growth - A guide for entrepreneurs". Cape Town: Juta and Co Ltd.

[19] Oketch, H. O. (2000). "Gender Equity. In A. Mullei and A. Bokea (Eds)." Micro and small Enterprises in Kenya: Agenda for improving the Policy Environment. Nairobi: ICEG.

[20] Parker, S. (2004)."The Economics of Self-Employment and Entrepreneurship, Cambridge:" University Press, Cambridge. pp. 10-178.
[21] Pearce A. J and Robinson R. B. (2007). "Strategic Management. London:" McGraw Hill.

[22] Perrot B, E (2008). "Managing strategy in turbulent environments." Journal of General Management Vol. 33 No. 3 spring 2008.

[23] Rami Alasadi and Ahmed Abdelrahim. (2007) "Critical Analysis and Modeling of Small Business Performance" (case Study: Syria). Journal of Asian Entrepreneurship and Sustainability, 3 (2):6-13.

[24] Schmidpeter, R., \& Weidinger, C. (2014). Linking business and society: An overview. In C. Weidinger (Ed.), Business success through sustainability (pp. 287-301). Berlin Heidelberg: Springer. https://doi.org/10.1007/978-3-64238753-1_1.

[25] Anne Ngima Kinyua. (Jan. 2014). "Factors Affecting the Performance of Small and Medium Enterprises in the Jua Kali Sector In Nakuru Town, Kenya", IOSR Journal of Business and Management (IOSR-JBM) e-ISSN: 2278-487X, p-ISSN: 2319-7668. Volume 16, Issue 1. Ver. IV (Jan. 2014), PP 80-93.

[26] SME Corp (2016). SME Annual Report 2016/2016. Retrieved 5 December 2016 from http://www.smecorp.gov.my/index.php/en/sme-annual-report2015-16.

[27] Stevenson, H. H. (2000). "Why Entrepreneurship Has Won", February, USASBE National Conference, Coleman White Paper, pp. 34-416. Supply Chain Management, Journal of Economics, 5 (3), pp. 247-257.

[28] Wanjiku Lily Njanja. (2009). "An Investigation into Management Strategies Affecting Performance of Micro, Small and Medium Enterprises (MSMES) In Kenya." University of South Africa.

[29] Watson C. H. (2001). "Small Business versus Entrepreneurship Revisited." Entrepreneurship Education: A Global View. Brockhaus. Burlington pp 46-47.

[30] Yamane, Taro. (1967). "Statistics: An Introductory Analysis, 2nd Ed., New York:" Harper and Row. 